EGU2020-18057

https://doi.org/10.5194/egusphere-egu2020-18057

EGU General Assembly 2020

(c) Author(s) 2020. This work is distributed under

the Creative Commons Attribution 4.0 License.

\title{
Humidity calibration of relative humidity devices in Martian conditions
}

Maria Hieta ${ }^{1}$, Maria Genzer ${ }^{1}$, Jouni Polkko ${ }^{1}$, lina Jaakonaho ${ }^{1}$, Andreas Lorek ${ }^{2}$, Stephen Garland ${ }^{2}$, Jean-Pierre de Vera ${ }^{2}$, German Martinez ${ }^{3,4}$, and Erik Fischer ${ }^{4}$

${ }^{1}$ Finnish Meteorological Institute (FMI), Helsinki, Finland (maria.hieta@fmi.fi)

${ }^{2}$ German Aerospace Center (DLR), Astrobiological Laboratories, Institute of Planetary Research, Berlin, Germany

${ }^{3}$ Lunar and Planetary Institute/USRA, Houston, TX, USA

${ }^{4}$ University of Michigan, Ann Arbor, USA

Finnish Meteorological Institute (FMI) has developed relative humidity measurement devices for past and future Mars lander missions: REMS-H for Curiosity, MEDA HS for Mars 2020 and METEO$\mathrm{H}$ for ExoMars 2020. The sensors used in these devices are HUMICAP $®$ capacitive thin-film polymer sensors by Vaisala Inc. New calibration measurements are performed with ground reference models of these devices in the Mars Simulation Facility (MSF) and Planetary Analog Simulation Laboratory (PASLAB) at the German Aerospace Center (DLR) in spring 2020. The preliminary results will be given at the EGU 2020.

Calibration of relative humidity devices requires in minimum two humidity points over the expected operational temperature and pressure range of the device. With two-point calibration the relative humidity devices can be used for scientific measurements with satisfactory quality but the uncertainty is notable. Stable humidity conditions between dry and saturation humidity in Martian conditions can be achieved reliably in very few laboratories in the whole world and humidity measurements in Martian conditions have been previously performed for the same devices in FMI laboratory and in Michigan Mars Environmental Chamber (MMEC) at the University of Michigan.

The new measurement campaign will consist of stable humidity point measurements in multiple temperatures between $+10^{\circ} \mathrm{C}$ to $-70^{\circ} \mathrm{C}$ in $\mathrm{CO}_{2}$ gas and Martian pressure of approximately $7 \mathrm{hPa}$. The measurements are performed simultaneously for multiple devices in a small pressure vessel with continuous humidified carbon dioxide flow.

The new measurement campaign will improve the characterization of the existing relative humidity devices in Mars lander missions and define in more detail the measurement uncertainties. 